Original Article

\title{
MICROBICIDAL POTENTIALITY OF PURIFIED ANTHOCYANIN FROM IN VITRO CULTURE OF CLERODENDRON INFORTUNATUM L. AGAINST SELECTED PATHOGENS
}

\author{
MEENU KRISHNAN V. G., GREESHMA MURUKAN, ASWATHY J. M., BOSCO LAWARENCE, MURUGAN K.* \\ Plant Biochemistry and Molecular Biology Laboratory, Department of Botany, University College, Trivandrum, 695034, Kerala \\ Email: harimurukan@gmail.com
}

Received: 12 Apr 2017 Revised and Accepted: 20 Apr 2018

\begin{abstract}
Objective: Clerodendron infortunatum L. is a widely used medicinal herb over centuries for curing many skin-borne disorders. The present study was designed to validate the tribal knowledge by evaluating antimicrobial potential of purified anthocyanin extracted from in vitro cell suspension culture.

Methods: The explants were inoculated on murashige and skoog (MS) medium mixed with various combinations of 2, 4-D a+BAP for callus induction. Green compact callus was initiated within $30 \mathrm{~d}$ from the explants on MS medium fortified with benzylaminopurine (BAP) (2.0 mg/l)+2, 4$\mathrm{D}(0.5 \mathrm{mg} / \mathrm{l})$. Subsequently, anthocyanin was triggered from the compact callus by subculturing in the medium containing 2 , 4-D and Kinetin. Cell suspension culture was also developed. Anthocyanin production was enhanced by elicitation using salicylic acid and others. Three chromatographic methods such as solid phase extraction by Sepharose C18 column, Oasis-MCX and Amberlite XAD 7+Sephadex LH 120 sorbents were used to purify the in vitro synthesized anthocyanin from the cell cultures. HPLC and molar absorptivity assay were carried to check the purity. Antimicrobial analysis was also carried using standard protocols to check minimum inhibitory concentration (MIC) and minimum killing concentration (MKC).

Results: The mean purity values obtained by high-performance thin layer chromatography (HPLC) were $90.9 \% \pm 1.9,80.60 \% \pm 2.3$ for 0 asis MCX, Amberlite XAD-7+Sephadex LH-20 column respectively. However, the purity by molar absorptivity was found to be less. HPLC chromatogram revealed 12 fractions of anthocyanin. Inhibition zone diameter, MIC and MKC values obtained for the purified anthocyanin revealed its antimicrobial potentiality but at different levels among the selected bacteria and fungi. C. albicans, S. aureus, P. aerugenosa showed significant values followed by MRSA, E. coli and A. flavus. The results are comparable with the synthetic antibiotics. However, E. faecalis was more resistance. Mode of action was confirmed from the results of intracellular potassium leakage and bacterial membrane integrity analysis.
\end{abstract}

Conclusion: Thus, the study confirms the efficacy of anthocyanin as natural antimicrobial and suggests the possibility of employing it as drugs for the treatment of infectious diseases caused by the pathogens.

Keywords: Clerodendron, HPLC, MS medium, Hormones, Anthocyanin, Column chromatography, Antimicrobial

(C) 2018 The Authors. Published by Innovare Academic Sciences Pvt Ltd. This is an open access article under the CC BY license (http://creativecommons.org/licenses/by/4.0/) DOI: http://dx.doi.org/10.22159/ijpps.2018v10i6.18649

\section{INTRODUCTION}

Antibiotics are one of the most important drugs in combating pathogenic infections and to safeguard the health-related quality of human life. However, over the past many decades, these antibiotics have become less effective against many pathogens and also produce toxic reactions. Similarly, the emergence of drug-resistant bacteria coupled with resistance against the common synthetic antibiotics created health hazards among human beings. Therefore, it is essential to find out new plant-based drugs with more potentiality. Drugs derived from herbal sources play a significant role in the prevention and treatment of many common diseases. In the least developed countries, ethnic medicine becomes part of their primary healthcare systems [1]. Herbals are commonly exploited in the ethnic medicine and their curative properties are well documented. Nearly, about $61 \%$ of herbal drugs are developed based on phytochemicals and they have been effective especially against infectious disease and lifestyle diseases [2]. However, recently the rate of active novel chemical entities related to microbicidal is declining [3]. Secondary metabolites of flowering plants may give a new source of microbicidal potential with possible novel mechanisms of action [4]. The bactericidal effects of ethno medicinal plant extracts have been studied by a large number of researchers around the world.

Plants possess a pool of secondary metabolites like tannins, terpenoids, alkaloids, flavonoids, glycosides, etc., which have been proved as antimicrobial under in vitro conditions. From pre-historic periods, herbal medicines have been used by common man. Medicinal potentiality of different indigenous herbals for many disorders has been documented by practitioners of traditional medicine [5]. Microbicidal powers of medicinal herbals are being increasingly reported from different parts of the earth. WHO estimates that herbal extracts or their active molecules are used as folk medicine in traditional therapies i.e., approximately $80 \%$ of the world population. Antibiotic resistance by microorganisms has increased due to their genetic ability to transmit and acquire resistance to synthetic drugs which are utilized as therapeutic agents.

In this juncture, Clerodendron infortunatum L. of Verbenaceae has been selected. In Ayurvedic literature, the species has been described to be useful against skin disorders and its use into the treatment of hematemesis, and leucoderma has been suggested [6]. Further, their pharmacological uses as pest and disease control agents were reported. Similarly, this plant is widely used by tribal people to treat various ailments including ringworm and other fungal skin infections. No scientific data was available regarding anthocyanin, in vitro culture and its microbicidal potentiality of $\mathrm{C}$. infortunatum. In this scenario, the present study was aimed to validate the ethnic knowledge of its microbicidal potential using anthocyanin.

\section{MATERIALS AND METHODS}

\section{Plant material}

Clerodendron infortunatum was collected from wild habitats of Kallar region, Ponmudi hills of Western Ghats. Identity was carried by referring floras and confirmed by referring herbarium of Jawaharlal Nehru Tropical Botanic Garden and Research Institute (JNTBGRI), Palode and voucher specimen was deposited in the Department of Botany, herbarium (UCB 2369).

\section{Plant material and in vitro culture}

Fresh excised leaves and nodes of $C$. infortunatum were employed as explants for culturing in the MS medium culturing [7]. The explants were surface sterilized, disinfected with teepol $(5 \% \mathrm{v} / \mathrm{v})$ for $20 \mathrm{~min}$ 
followed by mercuric chloride treatments $(0.01-0.2 \%$, for $1-5 \mathrm{~min})$. Subsequently, the explants were thoroughly washed with deionized water for thrice. The sterilized explants were dissected out into a suitable size and inoculated on MS medium fortified by sucrose (3\%) in $0.6 \%$ agar for solidification. $\mathrm{pH}$ was maintained to 5.8 , prior to autoclaving at $15 \mathrm{lb}$ pressure or $121^{\circ} \mathrm{C}$ for $20 \mathrm{~min}$. The cultures were kept at $25^{\circ} \mathrm{C}$ with a photoperiod of $12 \mathrm{~h}$.

The hormonal combinations in the MS medium supplemented were 2,4-dichlorophenoxyacetic acid (2,4-D)+Benzyl amino purine (BAP) $(0.5-3.0 \mathrm{mg} / \mathrm{l})$ and $\mathrm{BAP}+\mathrm{NAA}(0.5-3.0 \mathrm{mg} / \mathrm{l})$ for induction of callus. Callus obtained were sub-cultured in fresh MS medium with 2,4D+kinetin $(0.5-3.0 \mathrm{mg} / \mathrm{l})$ at different concentrations to generate pigmented callus.

Cell suspension cultures were derived from friable callus in $250 \mathrm{ml}$ Erlenmeyer flasks containing $100 \mathrm{ml}$ of liquid MS medium fortified with various concentrations of 2,4-D+Kin ( 0.5 to $3 \mathrm{mg} / \mathrm{l}$ ) in triplicates. The cell suspensions were kept at $110 \mathrm{rpm}$ on a rotary shaker at $25 \pm 1{ }^{\circ} \mathrm{C}, 3000$ lux and $16 / 8 \mathrm{~h}$ photoperiod. Cultures were retained for one month and their growth was determined by loss of weight by dissimilation.

Analysis was continued from $10^{\text {th }}$ to $25^{\text {th }}$ days using different types of elicitors such as salicylic acid, ethephon and precursors like phenylalanine and shikimic acid into the suspension cultures. Chemicals were sterilized through $0.22 \mu \mathrm{m}$ milipore filters and added at the time of inoculation to make the concentration of 50 $\mu \mathrm{l} / 25 \mathrm{ml}$ suspension culture. The cultures were maintained at $25 \pm 1$ ${ }^{\circ} \mathrm{C}$ under the continuous white fluorescent light on a rotary shaker.

\section{Estimation of anthocyanin content}

$1 \mathrm{~g}$ of in vitro pigmented cell mass was used for isolation and estimation of anthocyanin. The OD was recorded at 510 and $700 \mathrm{~nm}$ against distilled water as blank [8].

\section{Purification}

Crude anthocyanin extract was purified using three different protocols and was fractionated by HPLC-PDA.

(a) Sepharose packs solid-phase extraction (SPE. C18) was used. Giusti et al., [9] method were employed to yield maximum anthocyanin fraction. (b) Oasis-MCX SPE is a mixed mode between cation exchange and reversed-phase interactions. (c) Amberlite XAD-7 and Sephadex LH-20 SPE i.e., purification through 2 different cartridges. Initial purification was done with Amberlite XAD 7, and the resulted fraction was loaded into Sephadex LH 20 cartridge to separate anthocyanins from proanthocyanidins.

(b) HPLC-PDA and MS analysis were carried using Shimadzu HPLCphotodiode array (PDA) system equipped with a SPD-M20A PDA detector and also Shimadzu LCMS-2010 EV liquid chromatography. The mobile phase was solvent A: $4.5 \%$ formic acid in LC/MS grade water, and B: $0.1 \%$ formic acid in LC/MS grade acetonitrile.

\section{Microbial cultures and growth condition}

Freeze dried cultures of Staphylococcus aureus ATCC 25923, Enterococcus faecalis ATCC 29212, Escherichia coli ATCC 25922, Pseudomonas aeruginosa ATCC 27853, and Candida albicans ATCC 66027, Aspergillus flavus ATCC 16888 were purchased from Institute of microbial technology (IMTECH), Chandigarh. All test strains were reisolated three successive times on Mueller Hinton agar, MHA (Oxoid) to purify and identity was confirmed by standard bacteriological methods [10]. The inoculum size of each test strain was standardized according to the Committee for Clinical Laboratory Standards [11]. The test bacterial strain was inoculated into Mueller Hinton broth, MHB (Oxoid) medium and incubated for $3-6 \mathrm{~h}$ at $35^{\circ} \mathrm{C}$ in a shaker water bath until the culture attained a turbidity of 0.5 McFarland unit. The final inoculum was adjusted to $5 \times 105 \mathrm{cfu} / \mathrm{ml}$.

\section{Tube dilution assay}

The MIC values of purified anthocyanin from $C$. infortunatum were determined using two-fold broth microdilution to prepare extract concentrations of $100,50,25,12.5,6.3,3.2,1.6,0.8,0.4$, and $0.2 \mathrm{mg} / \mathrm{ml} ; 1$ $\mathrm{ml}$ of anthocyanin was added to test tubes containing $1 \mathrm{ml}$ of sterile $\mathrm{MH}$ media. The tubes were then inoculated with a drop of microbial suspension and incubated at $37{ }^{\circ} \mathrm{C}$ for $24 \mathrm{~h}$. Amphotericin B and tetracycline $(0.05 \mathrm{mg} / \mathrm{ml})$ were used as positive controls for the fungus and bacteria, respectively. Water was used as the negative control. The MIC value was determined macroscopically after $24 \mathrm{~h}$ of incubation in comparison with the growth and sterility controls $[10,11,12]$. MH plates were grouped into six different classes and labeled with the diverse concentrations on the base of the plates; these were used to plate out the contents of each tube in the respective sections of the plates. The plates were incubated for $18-24 \mathrm{~h}$ at $37^{\circ} \mathrm{C}$, after which the $\mathrm{MBC}$ were recorded. Six replicates were done for each extract concentration and controls against the bacteria and three replicates for the fungi [11].

\section{Well diffusion assay}

Antimicrobial susceptibility testing was done using the well diffusion method to detect the presence of anti-bacterial or antifungal activities of the plant samples [13]. A sterile swab was used to evenly distribute bacterial or fungal culture over the appropriate medium as stated previously. The plates were allowed to dry for 15 min before use in the test. Wells were then created and a pipette was used to place $30 \mu \mathrm{l}$ of anthocyanin from $C$. infortunatum into each well. The same extract was used on each plate; with a total of two plates used for each extract including two wells for the positive and negative controls. The negative and positive controls were the same as used in the tube dilution assay. The plates were incubated at $37^{\circ} \mathrm{C}$ for $24 \mathrm{~h}$ after which they were examined for inhibition zones. A caliper was used to measure the inhibition zones. Twelve replicates were done for each of the different concentrations, and each experiment was repeated six times to ensure reliability.

\section{Potassium (K+) leakage}

The potassium leakage was determined using a flame emission and atomic absorption spectroscopy used for titration in solution following the protocol of Edris et al.,[14]. The solution was filtrated after contact with the test compounds. The samples were analyzed in a GBC AAS 932 plus device using GBC Avante 1.33 software.

\section{Membrane integrity analysis using propidium iodide uptake}

The Live/Dead BacLight kit (Invitrogen) assesses membrane integrity by selective stain exclusion method of Simoes et al., [15]. This is a rapid method commonly used to determine both viable and total counts of bacteria [16].

\section{Statistical analysis}

The results of the analysis were expressed as the means of three independent analyses. The results of antimicrobial activity was analyzed by one-way analysis of variance (ANOVA) followed by Tukey test for multiple comparisons. The level of significance was set at $95 \%$. Statistical analysis was performed with statistical software SPSS 17 (SPSS for Windows; SPSS Inc, Chicago, IL).

\section{RESULTS AND DISCUSSION}

Pre-treatment with $0.1 \% \mathrm{HgCl}_{2}$ (2 min) was optimal to establish explants with a reduced rate of contamination and also showed maximum establishment (95\%) on medium. The leaf and nodal explants inoculated on MS medium fortified with various combinations of 2,4-D and BAP for callus induction. After $30 \mathrm{~d}$, leaf explants were proliferated into green compact callus (fig. 1) remarkably. Callogenesis revealed that the fresh weight of all the calli increased in MS media combinations of BAP+2,4 D (0.5-3 mg/l) compared to BAP+NAA $(0.5-2 \mathrm{mg} / \mathrm{l})$. The MS medium supplemented with $2 \mathrm{mg} / \mathrm{l} \mathrm{BAP}+0.5 \mathrm{mg} / \mathrm{l} 2,4 \mathrm{D}$ yielded the highest $(2.7 \pm 0.45 \mathrm{~g})$ callus fresh weight compared with other treatments. All the media combinations when fortified with BAP significantly improved the callus fresh weight indicating its importance for callus growth in Clerodendron comparing to 2, 4-D and NAA. The resulted callus was further subjected to sub-culturing to induce anthocyanin synthesis.

Further, sub-culturing of callus was attempted on MS medium fortified with 2,4-D and kinetin at different concentrations. Luxuriant pigmented callus was achieved on MS medium supplemented with $1 \mathrm{mg} / \mathrm{l} 2,4-\mathrm{D}+2 \mathrm{mg} / \mathrm{l}$ kinetin after $60 \mathrm{~d}$ of subculture i.e., $2.68 \pm 0.66 \%$. Increase in the concentration of $2,4-D$ 
and kinetin up to $5 \mathrm{mg} / \mathrm{l}$ decreased callogenic potentiality of the explants and which in turn the pigmentation (fig. 2). Interestingly, light is a major factor influencing the green callus formation with protocorm-like proliferation at $25^{\circ} \mathrm{C}$ and $12 \mathrm{~h}$ photoperiod with an irradiance of $60 \pm 2 \mu \mathrm{mol} / \mathrm{m}^{2} / \mathrm{sec}$.

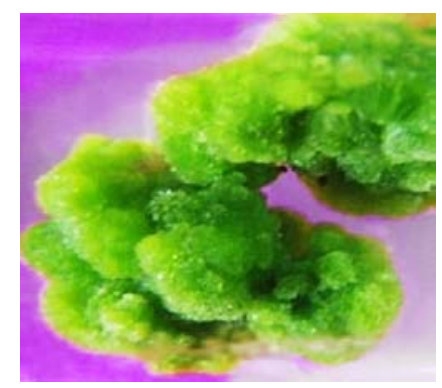

Fig. 1: Green compact callus on MS medium supplemented with $2.0 \mathrm{mg} / \mathrm{l}$ BAP+0.5 mg/l 2,4-D (30 d) of C. infortunatum L

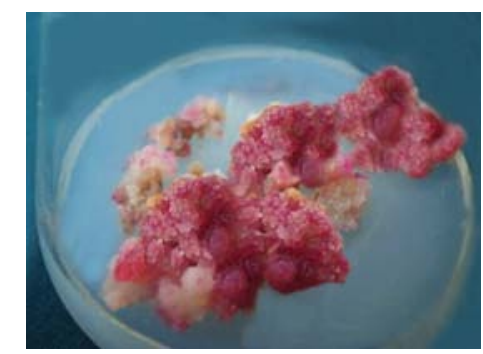

Fig. 2: Production of pigment callus of $C$. infortunatum in MS medium fortified with 2,4-D (1 mg/l) and kinetin (2 mg/l) (Kn)

Batch suspension cultures in triplicate were initiated with 2-3 g of friable callus as an inoculum at temperature $25 \pm 1{ }^{\circ} \mathrm{C}$ having photoperiod of $16-8$ at $110 \mathrm{rpm}$ in liquid MS medium supplemented with the same combinations of the growth regulators as those used in callus culture yielded transparent, homogeneous and nonchlorophyllous cultures which were used to evaluate the growth of biomass and anthocyanin content. Growth pattern of each culture was determined by loss of weight dissimilation method. Interestingly, the cultures yielded sigmoid curves with five growth phases i.e. lag, exponential, linear, stationary and progressive decline. The growth rates of cells were initially slow in the lag phase but as the cultures proceeded, the growth increased significantly and accumulated a great amount of fresh weight ( 4 fold) over a period of 20-25 d then the growth of cells became stable and started declining from $30^{\text {th }}$ day. Maximum growth was achieved in suspension culture supplemented with Kin (2.5 mg/l)+2, 4-D (0.5 mg/l) i.e., 3.86 \pm 0.01

Fresh Cell Weight (FCW) showed an increase marginally with salicylic acid (SA) and declined. The maximum fresh cell weight noticed was at $20^{\text {th }}$ day and subsequently declined i.e., $9.8 \pm 0.32$ FCW. Meanwhile, the anthocyanin content increased and attained a maximum value of $4.5 \pm 0.22$. Similarly, no sound variations were noticed with ethephon on the fresh cell weight and anthocyanin content. Further, phenylalanine and shikimic acid did not showed remarkable values on the fresh cell weight and anthocyanin content.

\section{Quantification of anthocyanin}

The anthocyanin content was quantified from the in vitro elicited cells and pigmented calli which showed a range from 1.7 to $4.5 \mathrm{mg} / \mathrm{g}$ monomeric anthocyanin i.e., approximately 5 fold increase compared with the in vivo seeds $(0.89 \mathrm{mg} / \mathrm{g})$.

The embryonic nature of agitated cells was analyzed using acetocarmine staining method. Pinkish coloured cells were noticed to indicate active embryonic cells. Subsequently, the anthocyanin extracted from the callus was subjected to TLC. 3 prominent bands were obtained in the chromatogram with yellow, dark violet and green-yellow colours having $\mathrm{Rf}$ values of $0.77,0.65$ and 0.511 respectively. Based on the Rf values anthocyanin was predicted as Cyanidin, delphinidin and malvidin based compounds. Further, the crude anthocyanin extract was subjected to purification with 3 different columns and further fractionated by HPLC-PDA analysis.

\section{Purity evaluation by HPLC-PDA and molar absorptivity}

The highest purity was found to be with Oasis MCX $(90.9 \% \pm 1.9)$ with molar absorptivity $90.9 \pm 1.9 \%$.

\section{Identification and quantification of anthocyanins}

The HPLC chromatogram of purified fractionated anthocyanin comprises 12 peaks (fig. 3). Based on literature data the elution order reported of anthocyanin derivatives were galactosides, glucosides and arabinosides. The fragmentation of delphinidin derivatives in MS2 yielded the formation of delphinidin aglycone $(m / z=302[\mathrm{M}+\mathrm{H}]+)$, after the characteristic release a 160 indicating the galactoside or glucoside in case of compounds 1 and 2, respectively and the release of 131 indicating the arabinoside unit in case of compound 4. Using a similar procedure, the identification of all other compounds was carried. Peaks were identified as 1-Delphinidin-3-0-galactoside, 2Delphinidin-3-0-glucoside, 3-Cyanidin-3-0-galactoside, 4-Delphinidin3-0-arabinoside, 5-Cyanidin-3-0-glucoside, 6-Petunidin-3-0galactoside, 7-Cyanidin-3-0-arabinoside, 8-Paeonidin-3-0-galactoside, 9-Petunidin-3-0-arabinoside, 10-Malvidin-3-O-galactoside, 11Malvidin-3-0-glucoside, 12-Malvidin-3-0-arabinoside.

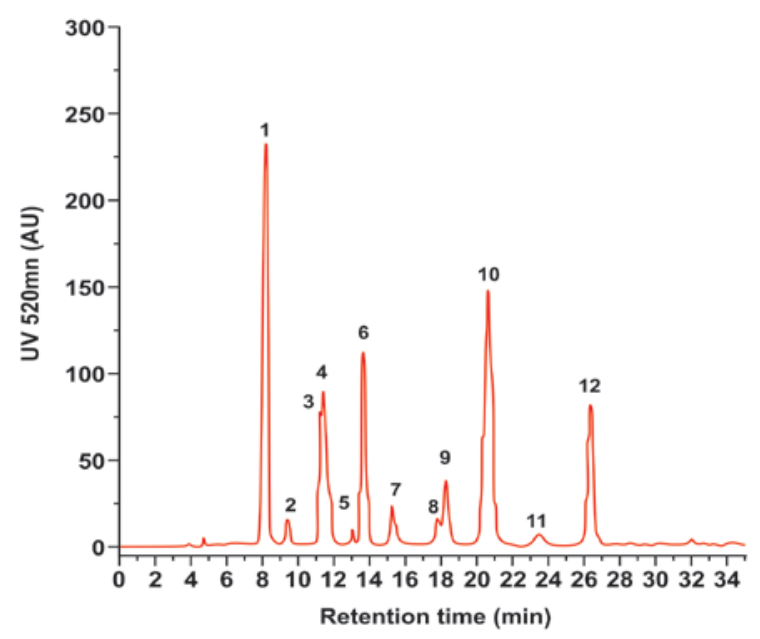

Fig. 3: HPLC-PDA chromatogram of purified anthocyanin of $C$. infortunatum $L$. 


\section{Antimicrobial potentiality}

The results illustrated in tables 1 and 2, indicated that purified anthocyanin of $C$. infortunatum showed antibacterial activity against both the Gram-positive (Staphylococcus aureus, MRSA, and E. faecalis), Gram-negative bacteria (Escherichia coli, Pseudomonas aeruginosa,) and antifungal potential among the selected fungi like Aspergillus flavus and Candida albicans. However, MKC of the purified anthocyanin extract against the Gram-positive bacteria was ranged from 0.8 to $6.4 \mathrm{mg} / \mathrm{ml}$, meanwhile, among the Gram-negative bacteria the values were 1.6 to $3.2 \mathrm{mg} / \mathrm{ml}$ ). Similarly, in the case of fungi, the MKC was also between $0.8-3.2 \mathrm{mg} / \mathrm{ml}$ ) (table 1).

In this study, the growth of MRSA was remarkably inhibited by the purified anthocyanin extract giving an MIC of $1.6 \mathrm{mg} / \mathrm{ml}$ by the tube dilution method and the inhibition zone as high as $20.8 \mathrm{~mm}$ by the well diffusion method. The anthocyanin extracts an average zone of inhibition for MRSA was less than that of non-methicillin resistant $S$. aureus $(26.5 \pm 0.45 \mathrm{~mm})$. The growth of $P$. aeruginosa was also inhibited but to a lesser extent with MIC of $0.8 \mathrm{mg} / \mathrm{ml}$ and inhibition zones as high as $22.5 \mathrm{~mm}$ (table 2). This is in comparison to the control Gentamicin (one of the commonly used anti-pseudomonal drugs), which produced inhibition zones of $28.6 \pm 0.44 \mathrm{~mm}$.

The results of the well diffusion assay corroborates with the results of the tube diffusion assay. For the Gram-positive bacteria, (Staphylococcus aureus, MRSA, and E. faecalis) zones of inhibition were all above $10.86 \pm 0.4 \mathrm{~mm}$ for the extract indicating their optimal antibacterial potency. For the Gram-positive bacteria Escherichia coli the anthocyanin extract produced the antibacterial activity with optimal MIC and MKC values (1.6 and $3.2 \mathrm{mg} / \mathrm{ml}$ ) and larger zones of inhibition (16.8 $\mathrm{mm}$ ) while for Pseudomonas aeruginosa the anthocyanin extract was more susceptible (Tables 1 and 2). Purified anthocyanin was effective in inhibiting the growth of the fungus $C$. albicans than $A$. flavus i.e., with a zone of inhibition of $25.2 \mathrm{~mm}$ and MIC and MKC values were 0.4 and $0.8 \mathrm{mg} / \mathrm{ml}$ respectively.

Table 1: MIC and MBC of purified anthocyanin of $C$. infortunatum using the tube dilution assay MRSA-multiple resistant $S$. aureus. mean $\pm S D, p<0.05$

\begin{tabular}{lll}
\hline Organism & MIC & MKC \\
\hline E. coli & $1.6 \pm 0.02$ & $3.2 \pm 0.38$ \\
P. aeruginosa & $0.8 \pm 0.09$ & $1.6 \pm 0.29$ \\
E. faecalis & $3.2 \pm 0.21$ & $6.4 \pm 1.5$ \\
S. aureus & $0.4 \pm 0.26$ & $0.8 \pm 0.076$ \\
MRSA & $1.6 \pm 0.09$ & $3.2 \pm 0.24$ \\
A. flavus & $1.6 \pm 0.06$ & $3.2 \pm 2.5$ \\
C. albicans & $0.4 \pm 0.01$ & $0.8 \pm 0.061$ \\
Tetracycline & $0.2 \pm 0.02$ & $0.4 \pm 0.04$ \\
Gentamicin & $0.4 \pm 0.01$ & $0.8 \pm 0.09$ \\
Vancomycin & $0.8 \pm 0.02$ & $1.6 \pm 0.08$ \\
Amphotericin & $0.8 \pm 0.05$ & $1.6 \pm 0.01$ \\
\hline
\end{tabular}

Results of agar diffusion method revealed a significant dose-dependent growth inhibitory activity against the Gram-positive bacteria $S$. aureus meanwhile, $E$. faecalis was found to be more resistant. With Gram-negative strains, only P. aeruginosa was found more sensitive. The zones of growth inhibition on $S$. aureus (Gram-positive) and $P$. aeruginosa, (Gram-negative bacteria), were maximum. Optimal zone of inhibition was noticed with E. coli compared to E. faecalis.

Table 2: Antimicrobial activity of purified anthocyanin of $C$. infortunatum determined by disk diffusion assay, mean \pm SD, $p<0.05$

\begin{tabular}{|c|c|c|c|c|c|c|c|}
\hline \multirow[t]{2}{*}{ Conc. $(\mathrm{mg} / \mathrm{ml})$} & \multicolumn{5}{|c|}{ Inhibition zone diameter (mm) } & \multirow[b]{2}{*}{ A. flavus } & \multirow[b]{2}{*}{ C. albicans } \\
\hline & E. coli & P. aeruginosa & E. faecalis & S. aureus & MRSA & & \\
\hline 1.0 & $2.46 \pm 0.31$ & $6.15 \pm 0.34$ & $1.93 \pm 0.98$ & $9.08 \pm 0.4$ & $7.6 \pm 0.67$ & $2.74 \pm 0.43$ & $10.4 \pm 0.21$ \\
\hline 1.5 & $7.51 \pm 0.43$ & $10.35 \pm 1.90$ & $4.39 \pm 0.98$ & $11.9 \pm 0.69$ & $9.8 \pm 0.55$ & $6.75 \pm 0.30$ & $12 \pm 1.4$ \\
\hline 2.0 & $10.2 \pm 0.69$ & $13.2 \pm 0.3$ & $6.44 \pm 0.77$ & $14.6 \pm 0.74$ & $12 \pm 0.04$ & $10.3 \pm 0.95$ & $14.6 \pm-0.32$ \\
\hline 2.5 & $12.5 \pm 0.1$ & $18.83 \pm 2.95$ & $8.12 \pm 0.95$ & $21.6 \pm 0.74$ & $17 \pm 0.94$ & $14.3 \pm 0.45$ & $19 \pm 0.16$ \\
\hline 3.0 & $16.8 \pm 0.4$ & $22.5 \pm 0.32$ & $10.86 \pm 0.4$ & $26.5 \pm 0.95$ & $20.8 \pm 0.21$ & $18.6 \pm 0.32$ & $25.2 \pm 0.92$ \\
\hline
\end{tabular}

The minimum biocidal concentration of anthocyanin was determined by incubating different concentrations of extracts with a standard inoculum of microbial cultures. After $24 \mathrm{~h}$ of incubation, an aliquot was removed from each test samples and the dilutions were plated on agar plates to determine the presence/absence of microbial colonies. The table 1 and 2 shows the antimicrobial activity of anthocyanin was comparable to the bactericidal effect of antibiotics. $C$. infortunatum has been used for centuries in India to counter the infective agents and also for other skin-borne medical ailments.

Table 3: Concentration of $\mathrm{k}+(\mu \mathrm{g} / \mathrm{ml})$ in solution of selected bacteria after $1 \mathrm{~h}$ of exposure to MIC of anthocyanin. mean $\pm \mathrm{SD}, p<0.05$

\begin{tabular}{ll}
\hline Pathogens & $\mathrm{K}+(\mu \mathrm{g} / \mathrm{ml})$ \\
\hline Staphylococcus aureus & $0.78 \pm 0.001$ \\
P. aeruginosa & $0.62 \pm 0.002$ \\
MRSA & $0.50 \pm 0.001$ \\
Escherichia coli & $0.38 \pm 0.005$ \\
Enterococcus faecalis & $0.29 \pm 0.007$ \\
\hline
\end{tabular}

Table 4: Permeability of bacteria to propidium iodide (pi) after $1 \mathrm{~h}$ of exposure to anthocyanin at their MIC mean \pm SD, $p<0.05$

\begin{tabular}{ll}
\hline Pathogens & Permeability to propidium iodide (\%) \\
\hline Staphylococcus aureus & $95 \pm 1.8$ \\
P. aeruginosa & $80.7 \pm 2.4$ \\
MRSA & $63.7 \pm 4.7$ \\
Escherichia coli $(-)$ & $50.5 \pm 0.74$ \\
Enterococcus faecalis $(+)$ & $37.8 \pm 0.99$ \\
\hline
\end{tabular}

Mean values \pm SD for at least three replicates are illustrated 


\section{Effects of anthocyanin on intracellular potassium leakage}

The $\mathrm{K}^{+}$leakage determination is used to identify alterations of the cell membrane permeability. The effects of anthocyanin on $\mathrm{K}^{+}$release from bacterial strains are shown in table 3. $0.78 \pm 0.001$ loss of intracellular $\mathrm{K}^{+}$was observed for Staphylococcus aureus cells with anthocyanin, at the tested concentration. For Enterococcus faecalis, $\mathrm{K}^{+}$leakage was found as $0.29 \pm 0.007$ (table 3).

\section{Effects of anthocyanin on bacterial membrane integrity}

The integrity of cell membranes can be assessed based on the ability of PI to penetrate the cytoplasmic membrane. PI only penetrates cells with damaged membrane. In this way, the potential of selected EOs components to interfere with membrane integrity afthr 1 exposure was analyzed (table 4). The PI uptake results suggest that anthocyanin compromise the integrity of the cytoplasmic membrane of both bacteria $(p<0.05)$. For Staphylococcus aureus the percentage of cells stained with PI after $1 \mathrm{~h}$ of treatment (at corresponding MIC) was $95 \pm 1.8 \%$. For MRSA exposed to anthocyanin, the damage in the cytoplasmic membrane was about $63.7 \pm 4.7 \%$ of the total cells (table 4). Sun et al., [16] analyzed the possibilities of multidrug resistance (MDR) that cause antibiotic resistance including target al. teration, drug inactivation, decreased permeability and increased efflux, drug extrusion by the multidrug efflux pumps serves as an important mechanism of MDR. In the present study, anthocyanin effectively alters the membrane permeability and therefore scope for further analysis among MDR strains.

The major metabolic reactions linked with microbicidal potentialities are glucorination, methylation and sulfation. Polyphenols are proven antimicrobial agents against human pathogens and have been intensively characterized to design novel healthy food ingredients as well as in medical and pharmaceutical fields. Meanwhile, only meager information is available about the microbicidal potentialities of the pure anthocyanins. However, there were a few reports about anthocyanin profiles of different berries and their antimicrobial potentialities with their identified compounds. Commonly, anthocyanins are active against many human microbes, however; Gram-positive bacteria are usually more sensitive to the anthocyanin than Gram-negative bacteria. The plausible mechanisms underlying anthocyanin activity may include both membrane and intracellular interactions of their functional groups. Microbicidal potentialities of fruits and other polyphenolcontaining berries are likely to be caused by multiple modes of actions. Anthocyanins contain diverse molecules including weak organic acids, phenolic acids and glycosides of different chemical forms [17].

Alberto et al. [18] experiments showed a direct relationship between the phenolic compounds of plant extracts and the antimicrobial power. Fruits of Aronia melanocarpa possess rich plant sources of phenolic substances, mainly anthocyaninsglycosides of cyanin. Anthocyanins are water-soluble pigments accounting for their dark blue color in the fruits $[2,3]$. They reported that anthocyanin content of berry fruits varies from $7.5 \mathrm{mg} / 100 \mathrm{~g}$ fresh fruit in red currant to $460 \mathrm{mg} / 100 \mathrm{~g}$ fresh fruit in Aronia melanocarpa. Cisowska et al., [19] confirmed that anthocyanins were active against various human pathogens, especially Gram-positive bacteria. The present results also showed that some Gram-positive bacteria and Gram-negative bacteria are more susceptible to purified anthocyanin. It is possible that such an effect could be due to anthocyanins. Liepina et al., [20] analyzed the antimicrobial activity of crude anthocyanin extracts from fruits of Aronia melanocarpa and Sorbus aucuparia. Cisowska et al., [19] reviewed anthocyanins as antimicrobial agents of natural plant origin. Burdulis et al., [21] compared anthocyanin composition, antimicrobial and antioxidant activity in bilberry and blueberry fruits. Liegiutè et al., [22] analyzed the composition of anthocyanin and its antimicrobial activity of sour cherry fruit extracts. Yoon et al., [23] analyzed anti-inflammatory and antimicrobial effects of anthocyanin extracted from black soybean on chronic bacterial prostatitis rat model. The antibactericidal activity of purified anthocynain of the present study against multi-resistant pathogens such as $S$. aureus (MRSA) and $P$. aeruginosa requires special attention. Srirangaraj et al., [24] analyzed multidrug-resistant
Acinetobacter baumannii from nosocomial urinary tract infection. Radhika and Mohaideen [25] analyzed the phytochemicals by fourier transform infrared analysis of Ulva lactuca and Gracilaria corticata and their effect on antibacterial activity. All these results substantiate the present result of $C$. infotunatum anthocyanin as microbicidal.

\section{CONCLUSION}

Calli initiation and growth were best with leaf explants on MS medium supplemented with $0.5 \mathrm{mg} / \mathrm{l} 2$, 4-D+2.0 mg/l BAP. But, the highest anthocyanin yield was obtained on MS medium added with $1.0 \mathrm{mg} / \mathrm{l}$ 2,4-D+2.0 mg/l KIN. The result showed that the calli growth and anthocyanin synthesis are inversely correlated. Cyanidin 3-0sambubioside, delphinidin 3-0-sambubioside and malvidin 3-0glucoside, delphinidin 3-0-glucoside, cyanidin 3-Oglucoside and petunidin 3-0-glucoside were minors. Malvidin 3-0-glucoside and petunidin 3-0-glucoside are the major anthocyanin noticed in the present study. This clearly shows an optimization of anthocyanins production by cells culture. Further, the study confirms the potentiality of anthocyanin as an antimicrobial against selected pathogens from bacteria and fungi and the results were comparable with the standards. Future studies are warranted to analyze the molecular mechanism of action of anthocyanin against the microbes.

\section{ACKNOWLEDGEMENT}

This major research project was supported by Kerala State Council for Science, Technology and Environment (KSCSTE), Govt. of Kerala.

\section{AUTHORS CONTRIBUTIONS}

All the author have contributed equally

\section{CONFLICTS OF INTEREST}

There are no conflicts of interest

\section{REFERENCES}

1. Bhalodia NR, Shukla VJ. Antibacterial and antifungal activities from leaf extracts of Cassia fistula L.: an ethnomedicinal plant. J Adv Pharm Technol Res 2011;2:104-9.

2. Valcheva Kuzmanova SV, Belcheva A. Current knowledge of Aronia melanocarpa as a medicinal plant. Folia Med 2006;48:11-7.

3. Kokotkiewicz A, Jaremicz Z, Luczkiewicz M. Aronia plants: a review of traditional use, biological activities, and perspectives for modern medicine. J Med Food 2010;13:255-69.

4. Chattopadhyay RR, Bhattacharyya SK. Herbal spices as alternative antimicrobial food preservatives: an update. Pharmacogn Rev 2007;1:239-47.

5. Chitra W, Calderon P, Gagnon D. Evaluation of selected medicinal plants extracted in different ethanol concentrations for antibacterial activity against human pathogens. J Medical Active Plants 2012;1:60-8.

6. Bhattacharjee D, Das A, Kanti Das S, Chakraborthy GS. Clerodendrum Infortunatum Linn.: a review. J Adv Pharm Healthcare Res 2011;1:81-5.

7. Murashige T, Skoog F. A revised medium for rapid growth and bioassays with tobacco tissue cultures. Physiol Plant 1962;15:473-97.

8. Rodrigues APM, Vendrame WA. Micropropagation of tropical woody species. In: Jain SM. Ishii K. Micropropagation of woody trees and fruits. Dordrecht: Kluwer Academic Publishers; 2003. p. 153-79.

9. Giusti MM, Wrolstad RE. Acylated anthocyanins from edible sources and their applications in food systems. Biochem Eng J 2003; 14:217-25.

10. Collins CH, Lyne PM. Microbiological Methods. Butterworth, London; 1970.

11. NCCLS. Methods for dilution antimicrobial susceptibility tests for bacteria that grow aerobically; Approved Standard-Fifth Edition. NCCLS document M7-A5. NCCLS: Wayne, PA, USA; 2000.

12. Demarsh PL, Gagnon RC, Hetzberg RP, Jaworski DD. Methods of screening for antimicrobial compounds. Smithkline Beccham Corporation. Publ World Intellectual Property Organization (WIPO); 2001.

13. Perez C, Pauli M, Bazerque P. An antibiotic assay by the agarwell diffusion method. Acta Biol Med Exp 1990;15:113-5. 
14. Edris AE, Farrag ES. Antifungal activity of peppermint and sweet basil essential oils and their major aroma constituents on some plant pathogenic fungi from the vapor phase. Food 2003; 47:117-21.

15. Simoes M, Pereira MO, Vieira MJ. Validation of respirometry as a short-term method to assess the efficacy of biocides. Biofouling 2005;21:9-17.

16. Sun J, Deng Z, Yan A. Bacterial multidrug efflux pumps: Mechanisms, physiology and pharmacological exploitations. Biochem Biophy Res Comm 2014;453:254-67.

17. Borges A, Simoes LC, Saavedra MJ, Simoes M. The action of selected isothiocyanates on bacterial biofilm prevention and control. Int Biodet Biodeg 2014;86:25-33.

18. Alberto MR, Canavosio MAR, Nadra MCM. Antimicrobial effect of polyphenols from apple skins on human bacterial pathogens. Electron J Biotechnol 2006;9:205-9.

19. Cisowska A, Wojnicz D, Hendrich AB. Anthocyanins as antimicrobial agents of natural plant origin. Nat Prod Commun 2011;6:149-56.

20. Liepina I, Nikolajeva V, Jakobsone I. Antimicrobial activity of extracts from fruits of Aronia melanocarpa and Sorbus aucuparia. Environ Exp Biol 2013;11:195-9.
21. Burdulis D, Äarkinas A, Jasutien I, Stackevilen E, Nikolajevas L, Janulis V. Comparative study of anthocyanin composition, antimicrobial and antioxidant activity in bilberry (Vaccinium myrtillus L.) and blueberry (Vaccinium corymbosum L.) fruits. Acta Poloniae Pharm Drug Res 2009;66:399-408.

22. Liegiutè S, Majienè D, Trumbeckaitè S, Liobikas J, Bendokas V, Stanys $\mathrm{V}$, et al. Anthocyanin composition and antimicrobial activity of sour cherry (Prunus cerasus L.) fruit extracts. Zemdirbystè (Agriculture) 2009;96:141-8.

23. Yoon BI, Bae WJ, Choi YS, Kim SJ, Syn Ha U, Hong S, et al. The anti-inflammatory and antimicrobial effects of anthocyanin extracted from black soybean on chronic bacterial prostatitis rat model. Chin J Integr Med 2013;23:1-6.

24. Srirangaraj S, Segar L, Kali A. Multidrug-resistant Acinetobacter baumannii from nosocomial urinary tract infection: a case report. Asian J Pharm Clin Res 2015;8:6-8.

25. Radhika D, Mohaideen A. Fourier transform infrared analysis of Ulva lactuca and Gracilaria corticata and their effect on antibacterial activity. Asian J Pharm Clin Res 2015;8:209-12. 